\title{
HUMANITIES
}

\section{Ideas about medical reporting}

\author{
Writing, Reading, and Understanding in \\ Modern Health Sciences. Medical Articles \\ and Other Forms of Communication \\ Milos Jenicek \\ CRC Press; 2014
}

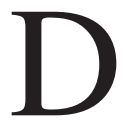

r. Jenicek would like us to write, read and understand medical articles better. He has in mind more the content of an article than its form: soul over the body, as he puts it. Although he distinguishes three types of medical articles, the book is mainly about research, and three main themes: thesis in its abstract sense; unambiguous and usable definitions of the terms of influence and measurement in the methods; and critical consideration of the findings and their meaning.

Having been promised a focus on substance rather than the form, the reader will be a little surprised to open

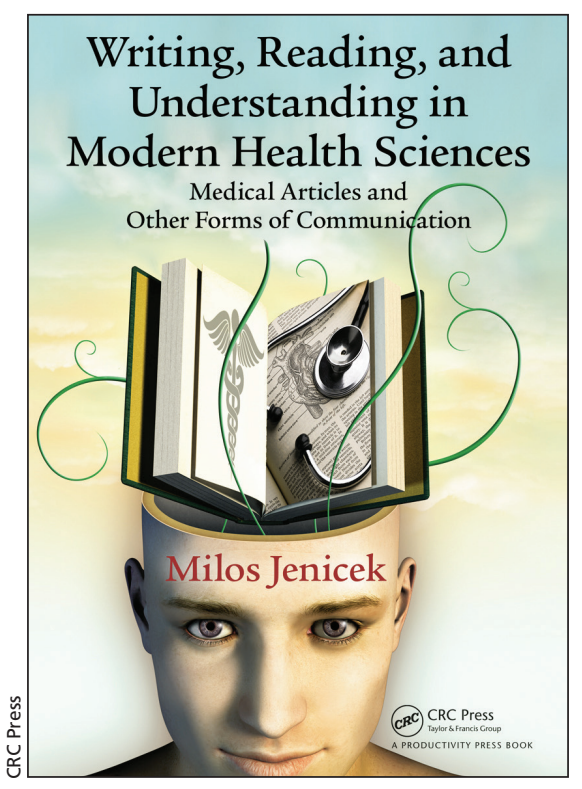

the chapter on "Thesis" to discover that its architecture has seven cornerstones. However, the text within is useful in giving a clear idea of the origin of each idea and its term, as well as its place in thesis development. In chapter four, he details no fewer than 15 types of definitions and then goes on to outline eight characteristics of a good definition. Chapters five and six cover the study results and their consideration, which he exhorts us to do in a spirit of critical thinking and logical argument.

This book delivers a helpful account as to how our ideas about medical reporting developed; it also sets out useful benchmarks as to what constitutes effective reporting. The novice researcher will read what a current standard is; the expert will nod assent frequently and be surprised by the background and helpful detail.

Still, effective writing is more learned than it is taught.

Kenneth Flegel MDCM MSc Senior Associate Editor, CMAJ

CMAJ 2015. DOI:10.1503/cmaj.140746 